\title{
Efektivitas IPAL portabel sebagai alternatif pengelolaan limbah cair domestik
}

\author{
I. B. Priyambada ${ }^{1}$, Purwono ${ }^{2 *}$ \\ ${ }^{1}$ Departemen Teknik Lingkungan, Fakultas Teknik, Universitas Diponegoro, Semarang, Indonesia \\ 2Ilmu Lingkungan, Institut Agama Islam Negeri, Surakarta, Indonesia
}

\begin{abstract}
Abstrak.
Di Indonesia, selain sebagai saluran air alamiah, sungai sering pula digunakan sebagai tempat pembuangan air limbah kegiatan rumah tangga (domestik). Penggunaan teknologi yang efisien dan alami merupakan solusi sederhana dan murah untuk mengolah air limbah domestik dengan sistem desentralisasi. Tujuan penelitian ini adalah mengolah air limbah domestik menggunakan IPAL portabel dengan dimensi kecil, sehingga aplikatif untuk skala rumah tangga. Penelitian dilakukan di Laboratorium Lingkungan, Departemen Teknik Lingkungan, Universitas Diponegoro selama 3 bulan. Metode penelitian menggunakan IPAL portabel untuk mengolah air limbah domestik skala rumah tangga dengan sistem kontinu. Limbah domestik berasal dari kantin kampus Universitas Diponegoro. IPAL portabel menggunakan sistem kombinasi anaerob-aerob yang dilengkapi dengan bak penampung limbah awal, bak penangkap lemak dan bak efluen. Waktu tinggal hidrolis atau Hydraulic Retention Time (HRT) dilakukan pada 3 variasi yaitu 4 jam, 8 jam dan 12 jam. Hasil penelitian menunjukkan bahwa konsentrasi amoniak mengalami penurunan terbesar pada HRT 12 jam dengan efisiensi penyisihan sebesar $60 \%$. Konsentrasi awal sebesar 40,99 mg/l turun menjadi $16,4 \mathrm{mg} / \mathrm{l}$. Konsentrasi Chemical Oxygen Demand (COD) dan minyak \& lemak juga mengalami penurunan terbesar pada HRT 12 jam, masing-masing turun sebesar $71 \%$ dan $91 \%$ dari konsentrasi awal. IPAL portabel ini paling efektif dalam menyisihkan minyak \& lemak.
\end{abstract}

\begin{abstract}
.
The reality in Indonesia shows that rivers beside as natural channels of water, often the river is used as a household or domestic waste water disposal. The use of efficient and natural technologies is a simple and inexpensive solution for treating domestic wastewater with a decentralized system. The purpose of this research was to treat domestic wastewater using portable and small dimension of WWTP, so that it is applicable for household scale. The research was conducted in Environmental Laboratory, Department of Environmental Engineering, Diponegoro University for 3 months. This research method used portable WWTP for treating domestic wastewater adopting continue system. Domestic waste came from the canteen of Diponegoro University. Portable WWTP used an anaerobic-aerobic combination system equipped with an initial waste basin, a grease catcher tube, and an effluent bath. Hydraulic retention time (HRT) was performed on 3 variations i.e. 4 hours, 8 hours, and 12 hours. The results showed that ammonia concentrations experienced the greatest decrease in HRT 12 hours with efficiency of $60 \%$. Initial concentrations of $40.99 \mathrm{mg} / \mathrm{l}$ dropped to $16.4 \mathrm{mg} / \mathrm{l}$. Chemical Oxygen Demand (COD) and oil and grease concentrations also experienced the largest decrease in HRT 12 hours by $71 \%$ and $91 \%$ of initial concentration. This portable WWTP was the most effective at removing oil and grease.
\end{abstract}

Keywords: ammonia, COD, portable WWTP, domestic waste water, oil and grease

Kata kunci: amoniak, COD, IPAL portabel, limbah domestik, minyak \& lemak

\section{PENDAHULUAN}

Pengumpulan dan pembuangan air limbah domestik di Indonesia masih menjadi permasalahan lingkungan yang cukup besar. Air limbah adalah campuran air dengan sejumlah besar bahan kimia (termasuk organik dan anorganik) dan logam berat yang berasal dari kegiatan domestik, industri dan komersial (Dixit et al. 2011). Sebagian besar air limbah kegiatan rumah tangga (domestik) dibuang secara langsung ke badan air seperti sungai dan danau.

\footnotetext{
${ }^{*}$ Korespondensi Penulis

Email : purwono.ga@gmail.com
} 
Manajemen limbah domestik yang tidak baik menyebabkan pencemaran terhadap badan air (Chen et al. 2006).

Penggunaan teknologi yang efisien dan alami merupakan solusi sederhana dan murah untuk mengolah air limbah domestik dengan sistem desentralisasi (Latrach 2016). Sistem desentralisasi memiliki ciri khas mengolah dan menggunakan kembali air limbah di lokasi yang sama (misalnya kebun, rumah dan kantor). Pengelolaan limbah domestik secara desentralisasi menekankan penyelesaian masalah limbah domestik tidak pada pengolahan komunal semata, akan tetapi tersebar di sumbernya masing-masing yaitu di tingkat rumah tangga. Sistem desentralisasi telah terbukti menjadi pilihan yang jauh lebih baik karena menghindari sistem pemipaan dan pengumpulan limbah ke Instalasi Pengolahan Air Limbah (IPAL) komunal. Teknologi yang ekonomis, terjangkau, ramah lingkungan dan dapat diterima secara sosial, maka teknologi harus murah, hemat energi, pemeliharaan mudah, efektif dan stabil (Aiyuk et al. 2004). Teknologi pengolahan air limbah terdesentralisasi telah berhasil digunakan untuk mengolah air limbah domestik di Jepang dan Thailand (Wakatsuki et al. 1993; Masunaga et al. 2007).

Pada umumnya, pengelolaan air limbah menggunakan sistem desentralisasi terdiri dari septic tank untuk pre-treatment dan efluen dialirkan ke badan air. Selanjutnya penyisihan parameter nitrogen dan fosfor menggunakan sistem wetland dan filter pasir. Namun, seiring pertumbuhan penduduk, biaya dan ketersediaan lahan menjadi faktor pembatas sistem wetland dan filter pasir (Aiyuk et al. 2004). IPAL portabel merupakan alternatif teknologi yang menjanjikan untuk mengatasi permasalahan tersebut.

Menurut Everhard (2001), industri di Australia telah memproduksi alat pengolah limbah dengan kapasitas 3000 liter/tangki. Kapasitas termasuk cukup besar apabila diterapkan dalam skala rumah tangga. IPAL portabel ini dilengkapi reaktor pengolahan primer, sekunder dan tersier yang tersusun dalam 2 tangki polimer. Pengolahan limbah cair menggunakan media lekat anaerob (biofilter) merupakan teknologi pengolahan yang murah, mudah operasinya serta hemat energi. Media lekat dapat berupa PVC, batu, pasir, biochart dan ijuk. Biofilter dapat digunakan untuk air limbah dengan beban COD yang cukup besar dan dapat menghilangkan padatan tersuspensi dengan baik. Air limbah domestik termasuk dalam kategori grey water.

Menurut Ajit (2016), karakteristik dari grey water sangat bervariasi, tergantung pada kebiasaan makanan dan tingkat kehidupan masing-masing individu. Air limbah yang berasal dari dapur kaya akan kandungan Total Suspended Solid (TSS), senyawa nitrogen (nitrat, nitrit, amonia dan nitrogen organik), minyak, lemak dan Biological Oxygen Demand (BOD). Air bekas kegiatan mandi dan mencuci akan menghasilkan lebih banyak Chemical Oxygen 
Demand (COD) dan fosfor. Kandungan tersebut mendukung adanya pencemaran. Selain itu juga terdapat polutan kimia seperti detergen dan pembersih lainnya (Lambe 2010; Suharto 2011).

Penelitian ini bertujuan untuk mengolah air limbah domestik menggunakan IPAL portabel dengan dimensi yang kecil sehingga aplikatif untuk skala rumah tangga. Dalam upaya mengatasi kelemahan timbulnya lapisan padat (scum) yang mengapung dan berbau, maka ditambahkan reaktor pemisah lemak dan minyak secara terpisah sebelum reaktor anaerob. Media lekat yang digunakan berupa ijuk yang tersedia dalam jumlah banyak, murah dan awet.

\section{METODOLOGI}

Peralatan yang digunakan dalam penelitian ini yaitu rangkaian IPAL Portabel. Air limbah mengalir secara gravitasi seperti ditampilkan pada Gambar 1 dengan pemasangan keran pada selang untuk mengatur debit seperti yang masuk ke dalam reaktor IPAL portabel. Dimensi reaktor sebesar $30 \times 30 \times 60 \mathrm{~cm}$ dengan volume efektif sebesar $45 \mathrm{~L}$. Reaktor terbuat dari bahan acrylic. Penelitian dilakukan di Laboratorium Lingkungan, Departemen Teknik Lingkungan, Fakultas Teknik, Universitas Diponegoro selama 3 bulan.

\subsection{Tahap aklimatisasi}

Proses ini dilakukan dengan melakukan seeding dengan starter limbah domestik selama 4 hari, kemudian melakukan aklimatisasi dengan mengisi IPAL portabel menggunakan air limbah selama kurang lebih 14 hari.

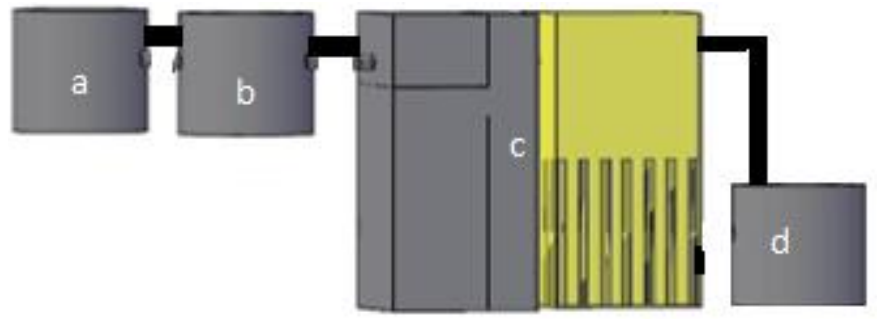

Gambar 1. Rangkaian alat IPAL portabel yang terdiri dari (a) bak penampung limbah awal $(\mathrm{p}=$ $19 \mathrm{~cm}, \mathrm{l}=18 \mathrm{~cm}$ dan $\mathrm{t}=23 \mathrm{~cm})$; (b) bak penangkap lemak $(\mathrm{p}=19 \mathrm{~cm}, \mathrm{l}=18 \mathrm{~cm}, \mathrm{t}=23 \mathrm{~cm})$; (c) reaktor IPAL portabel $(p=30 \mathrm{~cm}, \mathrm{l}=30 \mathrm{~cm}, t=60 \mathrm{~cm})$; (d) bak penampung efluen $(p=19 \mathrm{~cm}$,

$$
\mathrm{l}=18 \mathrm{~cm} \text { dan } \mathrm{t}=23 \mathrm{~cm}) \text {. }
$$

\subsection{Tahap running}

Gambar 1 menunjukkan rangkaian alat IPAL portabel. Ketika IPAL portabel siap digunakan, limbah siap diolah dengan mengalirkan air limbah ke dalam bak pengolahan pertama dan kedua diikuti variasi nilai HRT selama 4 jam, 8 jam dan 12 jam. Namun, sebelum dialirkan ke dalam reaktor dilakukan 
pengambilan sampel terlebih dahulu pada titik inlet IPAL portabel untuk uji laboratorium sebagai data konsentrasi awal limbah sebelum adanya perlakuan.

\subsection{Uji konsentrasi efluen IPAL portabel}

Melakukan uji laboratorium terhadap efluen IPAL portabel untuk parameter amoniak (metode Nessler), COD (metode spektrofotometri) SNI 066989.2-2004 dan minyak \& lemak (metode gravimetri). Pengujian dilakukan secara duplo untuk setiap sampel. Kemudian menganalisis hasil uji air limbah sebelum dan sesudah penggunaan IPAL portabel.

\section{HASIL DAN PEMBAHASAN}

Air limbah domestik yang digunakan dalam penelitian termasuk grey water. Limbah berasal dari dapur kantin Departemen Teknik Elektro, Universitas Diponegoro yang dihasilkan dari kegiatan mencuci peralatan makan dan masak. Jenis makanan yang disajikan setiap harinya relatif sama, jumlah pengunjung setiap harinya berbeda. Hal tersebut menyebabkan perbedaan karakteristik air limbah berbeda setiap harinya. Air limbah mengalir melalui saluran drainase yang terpelihara dengan baik. Konstruksi drainase sebagian berupa beton dan sebagian tanah. Ketika air limbah mengalir sekitar $\pm 100 \mathrm{~m}$, volume air limbah berkurang bahkan habis meresap ke dalam tanah. Karakteristik awal air limbah domestik tersebut ditunjukkan pada Tabel 1.

Tabel 1. Karakteristik awal air limbah yang berasal dari dapur kantin Departemen Teknik Elektro, Universitas Diponegoro.

\begin{tabular}{clcccc}
\hline No. & \multicolumn{1}{c}{ Parameter } & Satuan & Nilai & $\begin{array}{c}\text { Baku mutu } \\
\text { PerMenLHK Nomor } \\
68 \text { Tahun 2016) }\end{array}$ & Keterangan* \\
\hline 1 & Suhu & ${ }^{\circ} \mathrm{C}$ & 27 & - & - \\
2 & $\mathrm{pH}$ & - & 6,9 & $6-9$ & $\mathrm{M}$ \\
3 & BOD & $\mathrm{mg} / \mathrm{l}$ & 312 & 30 & $\mathrm{TM}$ \\
4 & COD & $\mathrm{mg} / \mathrm{l}$ & 3184,93 & 100 & $\mathrm{TM}$ \\
5 & TSS & $\mathrm{mg} / \mathrm{l}$ & 597 & 30 & $\mathrm{TM}$ \\
6 & TDS & $\mathrm{mg} / \mathrm{l}$ & 2488 & - & - \\
7 & Kekeruhan & $\mathrm{NTU}$ & $>1100$ & - & $\mathrm{TM}$ \\
8 & Minyak dan lemak & $\mathrm{mg} / \mathrm{l}$ & 1982 & 5 & - \\
9 & Nitrat & $\mathrm{mg} / \mathrm{l}$ & 78,3 & - & $\mathrm{TM}$ \\
10 & Amonia & $\mathrm{mg} / \mathrm{l}$ & 24,75 & 10 & - \\
11 & Total fosfat & $\mathrm{mg} / \mathrm{l}$ & 4,74 & - & $\mathrm{T}$ \\
\hline
\end{tabular}

*Keterangan: TM menandakan kadar parameter terukur tidak memenuhi baku mutu, sedangkan M menandakan memenuhi baku mutu.

Berdasarkan Tabel 1, konsentrasi COD, amoniak, serta minyak \& lemak masing-masing sebesar 3184,93 mg/l, 24,75 mg/l dan $1982 \mathrm{mg} / \mathrm{l}$ dengan nilai rasio BOD/COD sebesar 0,09. Ketiga parameter tersebut melebihi baku mutu 
yang ditetapkan dalam PerMenLHK Nomor 68 Tahun 2016 tentang Baku Mutu Air Limbah Domestik masing-masing sebesar $100 \mathrm{mg} / \mathrm{l}$ (COD), $100 \mathrm{mg} / \mathrm{l}$ (amonia) dan $5 \mathrm{mg} / \mathrm{l}$ (minyak \& lemak). Oleh karena itu, air limbah perlu diolah terlebih dahulu sebelum dilakukan pembuangan supaya tidak mencemari lingkungan. Parameter $\mathrm{pH}$ telah memenuhi baku mutu yang dipersyaratkan sehingga tidak perlu dilakukan pemantauan. Parameter yang melebihi baku mutu yaitu BOD dan TSS akan dilakukan penelitian pada tahap berikutnya sesuai dengan roadmap penelitian tahun 2018. Pada tahun yang sama juga akan dilakukan penelitian tentang nitrat dan total fosfat.

Air limbah tersebut digunakan untuk menganalisis penyisihan kadar COD, amoniak, serta minyak \& lemak menggunakan IPAL portabel. Tahap awal penelitian melakukan seeding dan aklimatisasi. Seeding merupakan proses pembenihan atau pemasukan mikroorganisme ke dalam reaktor hingga terlekat, tumbuh dan berkembang. Aklimatisasi adalah proses pengadaptasian mikroorganisme yang telah terbentuk dalam proses seeding (Indriyati 2003). Proses seeding dan aklimatisasi ditandai oleh efisiensi penyisihan COD yang relatif konstan (deviasi 10\%). Proses ini tercapai pada hari ke-9.

\subsection{Penyisihan chemical oxygen demand (COD)}

Pengukuran konsentrasi COD bertujuan untuk mengetahui jumlah oksigen yang dibutuhkan untuk mengoksidasi bahan-bahan organik dan anorganik menggunakan oksidator kuat berupa kalium dikromat (APHA 1998). Suhu tinggi $\left(150^{\circ} \mathrm{C}\right)$ dan suasana asam $\left(\mathrm{H}_{2} \mathrm{SO}_{4}\right.$ pekat) diperlukan agar kalium dikromat secara efektif mengoksidasi bahan-bahan organik dan anorganik. Reaksi yang terjadi ditunjukkan pada persamaan (1).

$\mathrm{C}_{\mathrm{a}} \mathrm{H}_{\mathrm{b}} \mathrm{O}_{\mathrm{c}}+\mathrm{Cr}_{2} \mathrm{O}_{7}^{2-}+\mathrm{H}^{+} \rightarrow \mathrm{CO}_{2}+\mathrm{H}_{2} \mathrm{O}+2 \mathrm{Cr}^{3+}$

Hasil penelitian menunjukkan bahwa waktu tinggal atau HRT selama 4 jam hanya mampu menyisihkan konsentrasi COD sebesar $24 \%$ dari konsentrasi awal sebesar 3544,52 mg/l. HRT 4 jam kemungkinan terlalu kecil sehingga laju pertumbuhan bakteri tidak cukup untuk menyisihkan polutan (Schnurer and Jarvis 2009). Efisiensi penyisihan meningkat menjadi 34\% pada HRT 8 jam. Efisiensi penyisihan tertinggi dicapai pada HRT 12 jam sebesar $71 \%$ dengan nilai konsentrasi COD outlet sebesar 1078,77 mg/l. Semakin besar HRT memungkinkan proses hidrolisis senyawa organik dan pembentukan lumpur anaerob menjadi lebih stabil (Pillay et al. 2006), akibatnya penyisihan COD semakin besar. Fenomena penurunan konsentrasi COD dalam IPAL portabel diakibatkan adanya proses anaerob pada bak 1, kemudian dilanjutkan proses aerob pada bak 2. Menurut Ajit (2016), apabila konsentrasi COD tinggi, maka proses anaerob dilakukan terlebih dahulu agar beban pengolahan pada proses aerob menjadi lebih ringan. 
Pada proses anaerob terjadi proses asidogenesis, asetogenesis dan metanogenesis, dengan produk akhir gas $\mathrm{CH}_{4}$ dan $\mathrm{CO}_{2}$. Senyawa organik pada proses anaerob mengalami reaksi sesuai persamaan (2), sedangkan pada bak 2 terjadi proses aerob sesuai persamaan (3) (Said dan Arie 2002).

Senyawa organik $\rightarrow \mathrm{CH}_{4}(\mathrm{~g})+\mathrm{CO}_{2}(\mathrm{~g})+\mathrm{H}_{2}(\mathrm{~g})+\mathrm{NH}_{3}(\mathrm{~g})+\mathrm{H}_{2} \mathrm{~S}(\mathrm{~g})$

Senyawa organik $+\mathrm{O}_{2}(\mathrm{~g}) \rightarrow \mathrm{CO}_{2}(\mathrm{~g})+\mathrm{H}_{2} \mathrm{O}(\mathrm{l}$

Secara keseluruhan, IPAL portabel ini belum mampu menyisihkan kandungan COD sampai $100 \mathrm{mg} / \mathrm{l}$ sesuai baku mutu PerMenLHK Nomor 68 Tahun 2016.

\subsection{Penyisihan Amoniak ( $\left.\mathrm{NH}_{4}-\mathrm{N}\right)$}

Baku mutu amoniak menurut PerMenLHK Nomor 68 Tahun 2016 sebesar $10 \mathrm{mg} / \mathrm{l}$. Hasil penelitian penyisihan amoniak menggunakan IPAL portabel ditampilkan pada Tabel 2 .

Tabel 2. Efisiensi penyisihan kandungan amoniak terhadap variasi HRT.

\begin{tabular}{ccccccc}
\hline & \multicolumn{5}{c}{ Kandungan amonia (mg/l) } \\
\cline { 2 - 6 } $\begin{array}{c}\text { HRT } \\
\text { (jam) }\end{array}$ & Inlet & $\begin{array}{c}\text { Setelah bak } \\
\text { penangkap lemak }\end{array}$ & $\begin{array}{c}\text { Antara bak } \\
\text { anaerob dan } \\
\text { aerob }\end{array}$ & Outlet & $\begin{array}{c}\text { (inlet- } \\
\text { outlet) }\end{array}$ & $\begin{array}{c}\text { Efisiensi } \\
(\%)\end{array}$ \\
\hline 4 & 25 & 24,24 & 23,84 & 22,48 & 2,52 & 10 \\
8 & 40,11 & 39,15 & 32,78 & 23,05 & 17,06 & 43 \\
12 & 40,999 & 40,71 & 30,04 & 16,4 & 24,599 & 60 \\
\hline
\end{tabular}

Berdasarkan Tabel 2, efisiensi penyisihan amoniak meningkat seiring dengan HRT yang semakin lama. Pada HRT 4 jam, IPAL portabel mampu menyisihkan amoniak 10\% dari konsentrasi awal $25 \mathrm{mg} / \mathrm{l}$. Efisiensi penyisihan amoniak sebesar 43\% dan 60\% masing-masing dihasilkan pada HRT 8 dan 12 jam. Menurut Herald dan Diana (2001), penurunan konsentrasi amoniak akibat proses nitrifikasi secara aerob. Nitrogen dalam keadaan oksidasi N (III) dikonversi menjadi $\mathrm{N}(\mathrm{V})$ seperti persamaan reaksi (4).

$1 / 4 \mathrm{O}_{2}+1 / 8 \mathrm{NH}_{4}^{+} \longrightarrow 1 / 8 \mathrm{NO}_{3}{ }^{-}+4 \mathrm{H}^{+}+8 \mathrm{H}_{2} \mathrm{O}$

Media lekat berupa ijuk berperan sebagai media lekat biofilm. Lapisan terluar biofilm merupakan lapisan aerob, yang mana akan terjadi proses oksidasi senyawa amoniak menjadi senyawa transisi nitrit. Selanjutnya diikuti proses oksidasi nitrit menjadi senyawa nitrat atau disebut proses nitrifikasi. Setelah itu akan terjadi pengolahan anaerob pada lapisan biofilm. Pada lapisan ini, senyawa nitrat yang terbentuk dari proses oksidasi amoniak, diolah lebih lanjut menjadi gas nitrogen $\left(\mathrm{N}_{2}\right)$. Nitrosomonas terlibat dalam tahapan nitritasi yaitu tahap oksidasi ion amonium $\left(\mathrm{NH}_{4}^{+}\right)$menjadi ion nitrit $\left(\mathrm{NO}_{2}^{-}\right)$dan Nitrobacter terlibat di dalam tahap nitrasi, yaitu tahap kedua proses nitrifikasi. 
Secara keseluruhan variasi ketiga HRT tersebut belum mampu menyisihkan amoniak sampai baku mutu yang ditetapkan sebesar $10 \mathrm{mg} / \mathrm{l}$. Konsentrasi amoniak terendah sebesar 16,4 mg/l. IPAL portabel ini belum cukup efektif menyisihkan kadar amoniak dalam air limbah dapur kantin Departemen Teknik Elektro, Universitas Diponegoro.

\subsection{Penyisihan minyak dan lemak}

Penyisihan konsentrasi minyak dan lemak dalam limbah kantin Departemen Teknik Elektro ditunjukkan pada Tabel 3.

Tabel 3. Efisiensi penyisihan kandungan minyak dan lemak terhadap variasi HRT.

\begin{tabular}{ccccccc}
\hline \multirow{2}{*}{$\begin{array}{c}\text { HRT } \\
\text { (jam) }\end{array}$} & $\begin{array}{c}\text { Kandungan } \\
\text { awal }\end{array}$ & $\begin{array}{c}\text { Setelah bak } \\
\text { penangkap lemak }\end{array}$ & $\begin{array}{c}\text { Antara bak anaerob } \\
\text { dan aerob }\end{array}$ & Outlet & $\begin{array}{c}\text { (awal- } \\
\text { outlet) }\end{array}$ & $\begin{array}{c}\text { Efisiensi } \\
(\%)\end{array}$ \\
\hline 4 & 1788 & 1294 & 1098 & 680 & 1108 & 62 \\
8 & 508 & 300 & 288 & 112 & 396 & 78 \\
12 & 428 & 236 & 210 & 40 & 388 & 91 \\
\hline
\end{tabular}

Efisiensi penyisihan minyak dan lemak tertinggi sebesar 91\% dicapai pada saat HRT 12 jam dengan konsentrasi efluen sebesar 40 mg/l. HRT 4 jam dan 8 jam menghasilkan efisiensi penyisihan masing-masing 62\% dan 78\%. Peran bak penangkap lemak dan minyak cukup efektif menyisihkan lemak \& minyak. Sebagai contoh pada HRT 12 jam konsentrasi minyak \& lemak awal sebesar 428 $\mathrm{mg} / \mathrm{l}$ turun menjadi $40 \mathrm{mg} / \mathrm{l}$, dengan kata lain IPAL portabel mampu menyisihkan minyak \& lemak sebesar $380 \mathrm{mg} / \mathrm{l}$. Bak penangkap lemak didesain berdasarkan perbedaan massa jenis, minyak dan air akan terpisah karena massa jenisnya yang berbeda. Menurut Syafila et al. (2013) berat jenis air pada kondisi Standard Temperature and Pressure (STP) sebesar $1 \mathrm{~g} / \mathrm{cm}^{3}$ (setiap $1 \mathrm{~cm}^{3}$ air beratnya adalah $1 \mathrm{~g}$ ), sedangkan berat jenis minyak sekitar $0,8 \mathrm{~g} / \mathrm{cm}^{3}$. Ketinggian bak penangkap minyak \& lemak hampir sama dengan outlet IPAL Portabel. Hal tersebut dilakukan dengan harapan minyak yang terapung akan mengalir ke terjunan sebelum keluar melalui pipa outlet.

Menurut Ahmad et al. (2011) selain bak penangkap lemak, penyisihan minyak dan lemak terjadi akibat proses anaerob dan aerob pada IPAL Portabel. Pada proses anaerob, terjadi hidrolisis senyawa minyak dan lemak melalui beberapa tahap yakni tahap pembentukan asam (proses hidrolisis, asidogenesis dan asetogenesis) dan tahap pembentukan metana (proses metanogenesis).

\section{KESIMPULAN DAN SARAN}

Instalasi Pengolahan Air Limbah (IPAL) portabel untuk mengolah air limbah domestik skala rumah tangga sangat efisien untuk menyisihkan minyak \& lemak mencapai 91\% dengan HRT 12 jam. Penyisihan COD dan amoniak 
masing-masing sebesar $60 \%$ dan 71\%. Dalam penelitian hanya difokuskan pada variasi HRT terhadap penyisihan polutan limbah domestik dan kriteria desain IPAL portabel tidak dipertimbangkan.

\section{UCAPAN TERIMA KASIH}

Terima kasih kepada Departemen Teknik Lingkungan, Fakultas Teknik, Universitas Diponegoro atas pendanaan penelitian ini melalui DIPA anggaran tahun 2017.

\section{DAFTAR PUSTAKA}

Ahmad A, Syarfi dan Atikalidia M. 2011. Penyisihan chemical oxygen demand (COD) dan produksi biogas limbah cair kelapa sawit dengan bioreaktor hibrid anaerob bermedia cangkang sawit [Prosiding]. Prosiding Seminar Nasional Teknik Kimia "Kejuangan" A03:1-8.

Aiyuk S, Amoako J, Raskin L, van Haandel A and Verstraete W. 2004. Removal of carbon and nutrients from domestic wastewater using a low investment, integrated treatment concept. Water Research 38(13):3031-3042.

Ajit K. 2016. A review on grey water treatment and reuse. International Research Journal of Engineering and Technology (IRJET) 3(5):2665-2668.

[APHA] American Public Health Association. 1998. Standard methods for the examination of water and wastewater $17^{\text {th }}$ ed. American Public Health Association, American Water Works Association and Water Pollution Control Federation. Washington DC.

Chen M, Chen J and Du P. 2006. An inventory analysis of rural pollution loads in China. Water Science Technology 54(11-12):65-74.

Dixit A, Dixit S and Goswami CS. 2011. Process and plants for wastewater remediation: a review. Scientific Reviews and Chemical Communications 11:71-77.

Everhard. 2001. Clearwater treatment industries: aqua nova. Everhard Industries. Queensland.

Herald D dan Diana A. 2001. Penyisihan amonia, nitrit dan nitrat dari limbah cair hotel dengan metode multi soil layering (MSL) studi kasus: limbah Hotel Pangeran Beach, Padang [internet]. Tersedia di: http://repo.unand.ac.id/ 2908.

Indriyati. 2003. Proses pembenihan (seeding) dan aklimatisasi pada reaktor tipe fixed bed. Jurnal Teknologi Lingkungan 4(2):54-60.

Lambe JS. 2010. Greywater-treatment and reuse. Journal of Mechanical and Civil Engineering 10(3):20-26. 
Latrach L. 2016. Domestic wastewater disinfection by combined treatment using multi-soil-layering system and sand filters (MSL-SF): a laboratory pilot study. Ecological Engineering 19(91):294-301.

Masunaga T, Sato K, Mori J, Shirahama M, Kudo H and Wakatsuki T. 2007. Characteristics of wastewater treatment using a multi-soil-layering system in relation to wastewater contamination levels and hydraulic loading rates. Soil Science Plant Nutrition 53(2):215-223.

PerMenLHK (Peraturan Menteri Lingkungan Hidup dan Kehutanan) Nomor 68 Tahun 2016 tentang baku mutu air limbah domestik.

Pillay S, Foxon K, Rodda N, Smith MT and Buckley CA. 2006. Microbiological studies of an anaerobic baffled reactor (ABR). South African National Research Foundation and University of KwaZulu-Natal. South African.

Said NI dan Arie H. 2002. Teknologi pengolahan air limbah. Badan Pengkajian dan Penerapan Teknologi (BPPT). Jakarta.

Schnurer A and Jarvis A. 2009. Microbiological handbook for biogas plants. Svenskt gastekniskt center AB. Malmo.

[SNI] Standar Nasional Indonesia 06-6989.2-2004. 2004. Air dan air limbahbagian 2: cara uji kebutuhan oksigen kimiawi (KOK) dengan refluks tertutup secara spektrofotometri. Badan Standardisasi Nasional. Jakarta.

Suharto I. 2011. Limbah kimia dalam pencemaran udara dan air. Andi Offset. Yogyakarta.

Syafila M, Djajadiningrat A dan Handajani M. 2013. Kinerja bioreaktor hibrid anaerob dengan media batu untuk pengolahan air buangan yang mengandung molase. Journal of Mathematical and Fundamental Sciences 35(1):19-31.

Wakatsuki T, Esumi $\mathrm{H}$ and Omura S. 1993. High performance and $\mathrm{N}$ and $\mathrm{P}$ removable on-site domestic waste water treatment system by multi-soillayering method. Water Science Technology 27(1):31-40. 